\title{
Individual Growth Model for Eucalyptus Stands in Brazil Using Artificial Neural Network
}

\author{
Renato Vinícius Oliveira Castro, ${ }^{1}$ Carlos Pedro Boechat Soares, ${ }^{2}$ Helio Garcia Leite, ${ }^{2}$ \\ Agostinho Lopes de Souza, ${ }^{2}$ Gilciano Saraiva Nogueira, ${ }^{3}$ and Fabrina Bolzan Martins ${ }^{4}$ \\ ${ }^{1}$ Department of Forestry, Faculty of Technology, University of Brasília, Campus Darcy Ribeiro, 70904-970 Brasília, DF, Brazil \\ ${ }^{2}$ Department of Forestry, Federal University of Viçosa, Campus UFV, 36570-000 Viçosa, MG, Brazil \\ ${ }^{3}$ Department of Forestry, Federal University of the Valleys of Jequitinhonha and Mucuri, Campus Diamantina, \\ 39100-000 Diamantina, MG, Brazil \\ ${ }^{4}$ Natural Resources Institute, Federal University of Itajubá, Campus Itajubá, 37500-903 Itajubá, MG, Brazil
}

Correspondence should be addressed to Renato Vinícius Oliveira Castro; castrorvo@ymail.com

Received 13 December 2012; Accepted 14 February 2013

Academic Editors: J. Kaitera, P. Newton, T. L. Noland, and P. Robakowski

Copyright (C) 2013 Renato Vinícius Oliveira Castro et al. This is an open access article distributed under the Creative Commons Attribution License, which permits unrestricted use, distribution, and reproduction in any medium, provided the original work is properly cited.

\begin{abstract}
This work aimed to model the growth and yield of Eucalyptus stands located in northern Brazil, at the individual tree level, by using artificial neural networks (ANNs). Data from permanent plots were used for training the neural networks to predict tree height and diameter as well as mortality probability. Once trained, the networks were evaluated using an independent data set. The first group was composed of 33 plots (11 in each productive capacity class) and was used for artificial neural network training. In five measurements, this group totaled 8,735 cases (measurements of individual trees), as each plot had 53 trees on average throughout this evaluation. The second group was composed of 30 plots (10 in each productive capacity class) and was used for model validation. This group totaled 7,756 cases. Were tested different network architectures Multilayer Perceptron (MLP). Results revealed an underestimation bias for number of surviving trees. However, estimates of diameter, height, and volume per hectare were found to be accurate. This indicates that artificial neural networks are a viable alternative to the traditional growth and yield modeling approach in the forestry sector.
\end{abstract}

\section{Introduction}

Individual tree models are constituted by a set of submodels that estimate diameter and height growth as well as mortality probability through tree- and stand-related variables and through competition data [1-3]. According to Munro [4], these models may be categorized according to how they consider the competition among trees, as represented by distance-dependent and distance-independent models.

Since Newnham [5], many studies have been conducted worldwide in an attempt to improve growth models at the individual tree level and the relevant submodels. Methods to estimate parameters as well as different explanatory variables have been evaluated in an attempt to produce accurate, unbiased estimates of diameter and height growth and also tree mortality [6,7]. In Brazil, few studies have been conducted that used these types of growth model for Eucalyptus [8, 9], a genus whose planted area intended to supply the processing industry amounts to 4.75 million hectares [10]. Some models have been developed and fitted for some species, including canjerana (Cabralea canjerana), black cinnamon (Nectandra megapotamica), cedar (Cedrela fissilis), and araucaria (Araucaria angustifolia), in natural forest conditions, yet without computing all the submodels that compose an individual tree model [11-14].

Typically, estimates of equation parameters for the models are derived from linear and nonlinear regressions $[15,16]$. However, other estimation techniques that include artificial neural networks have been successfully used in forest mensuration [17-22], providing just as accurate estimates as those derived through regression, models [23-25]. 
Artificial neural networks (ANNs) are a type of artificial intelligence system similar to human brain, having a computational capability which is acquired through learning [26]. They can be used in data classification, time series analysis or regression, and pattern recognition [27-29].

Artificial neurons are processing units composed of an activation function which is also known as transfer function. This function is applied to a linear combination among the input variables and weights that reach a given neuron and then returns an output value $[19,28]$.

The architecture of an artificial neural network refers to how neurons are organized. They comprise three layers: an input layer where variables are introduced to the network, a hidden or intermediate layer where most of the signal processing occurs, and an output layer where the end result is completed and presented.

MLP (Multilayer Perceptron) is the most widely used artificial neural network model for predicting continuous variables. In MLP training, network functioning is as follows: each neuron is connected to every neuron in the subsequent layer; there are no connections between neurons in the same layer; it has at least one processing hidden layer and a high connectivity level between neurons, which is defined by synaptic weights.

The input layer distributes the inputs to subsequent layers. Input nodes have liner activation functions and no thresholds. Each hidden unit node and each output node have thresholds associated with them in addition to the weights. The hidden unit nodes have nonlinear activation functions and the outputs have linear activation functions. Hence, each signal feeding into anode in a subsequent layer has the original input multiplied by a weight with a threshold added and then is passed through an activation function that may be linear or nonlinear (hidden units) [28]. Only three layer MLPs will be considered in this work since these networks have been shown to approximate any continuous function.

According to this architecture, an approximation was obtained of an unknown function $f(x)$ that describes the mapping of input $(x)$-output $(y)$ pairs of a set of $n$ training patterns [28].

The ANN method was successfully used for modeling regular mortality of individual trees of Quercus coccínea [30] and survival of Pinus resinosa [31]; for predicting some functional characteristics of ecosystems [23]; for classifying wood using CT scans [32]; for modeling growth rings using climate variables in Pseudotsuga menziesii [33]; for comparing different types of ANN in mortality estimates of Picea abies [19]; for classifying forest inventory methods [34]; for predicting forest attributes using treetop, soil, and tree size variables [35]; for estimating volume outside bark of Pinus brutia [20]; for estimating trunk volume of Pinus brutia, Abies cilicica, Cedrus libani, and Pinus sylvestris [36] among others. All studies being cited demonstrate the great potential of ANNs for the use in several forest engineering fields, in particular forest mensuration and management.

In Brazil, despite there being more than 4 million hectares planted with Eucalyptus species [10], the use of neural networks as an alternative methodology to regression models is still incipient $[20,36]$; the latter is the traditional method for
TABLE 1: Characteristics of Eucalyptus grandis $\times$ Eucalyptus urophylla stands located in Monte Dourado, Pará state, Brazil.

\begin{tabular}{lc}
\hline Age (months) & $24-72$ \\
Diameter at breast height: $\overline{\text { d.b.h. }}(\mathrm{cm})$ & $4.0-29.4$ \\
Average diameter: $q(\mathrm{~cm})$ & $7.3-18.4$ \\
Total height: $\mathrm{Ht}(\mathrm{m})$ & $8.5-34.1$ \\
Dominant height: $\mathrm{Hd}(\mathrm{m})$ & $13.1-34.8$ \\
Basal area $\left(\mathrm{m}^{2} \mathrm{ha}^{-1}\right)$ & $4.7-27.2$ \\
Volume $\left(\mathrm{m}^{3} \mathrm{ha}^{-1}\right)$ & $23.8-353.9$ \\
Density $\left(\mathrm{trees} \mathrm{ha}^{-1}\right)$ & $760-1180$ \\
\hline
\end{tabular}

$\overline{\text { d.b.h. }}=\sum_{i=1}^{n}$ d.b.h. ${ }_{\cdot} / n, q=\sqrt{\sum_{i=1}^{n} \text { d.b.h. }_{. i}{ }^{2} / n}$, Ht is the distance between the ground and the top of the tree, and Hd is the five trees heights of largest d.b.h. on each plot.

growth and yield modeling in the forestry sector. With that in mind, this work aimed to model the growth of Eucalyptus stands at the individual tree level by using artificial neural networks.

\section{Material and Methods}

2.1. Data. Data were obtained from 63 permanent plots, approximately $500 \mathrm{~m}^{2}$ in area, containing clonal stands of Eucalyptus grandis $\times$ Eucalyptus urophylla, with initial spacing of $3 \times 3 \mathrm{~m}$ between plants (Table 1 ). This study was conducted in the municipality of Monte Dourado, Pará state, on the banks of river Jari, northern Brazil (Figure 1). The equations to estimate volume with bark are presented in Table 2. Local soil types include yellow latosols, cambisols, and podzols. The local climate is characterized as equatorial, hot, and humid, with a rainfall regime (average annual rainfall of 2,115 mm) marked by two well-defined seasons, with a rainy period from January to July which accounts for about $80 \%$ of the annual precipitation and a dry period from August to December. Regards the wind regime, the average wind speed is 2 to $4 \mathrm{~m} \mathrm{~s}^{-1}$. Wind blasts are nonetheless common, potentially exceeding $100 \mathrm{~km} \mathrm{~h}^{-1}$ in some cases. The predominant natural vegetation is the submontane and montane dense moist forest type. The average annual temperature is $26.4^{\circ} \mathrm{C}[9,37]$.

In every permanent plot, measurements were taken of the diameter at breast height (d.b.h.) using a measuring tape, and total height $(\mathrm{Ht})$ of each tree, using a digital hypsometer, for five annual measurements $(24,36,48,60$, and 72 months). The last measurement is equivalent to the age of cutting forest. The volume with bark $(V)$ was derived using equations provided by a local forest company. The height of dominant trees $(\mathrm{m})$ was used for productive capacity classification through site indices $(S)$ [15]. The site index curves were constructed employing the guide curve method assuming the index age of 60 months.

The set of permanent plots was randomly divided into two groups. The first group was composed of 33 plots (11 in each productive capacity class)and was used for artificial 


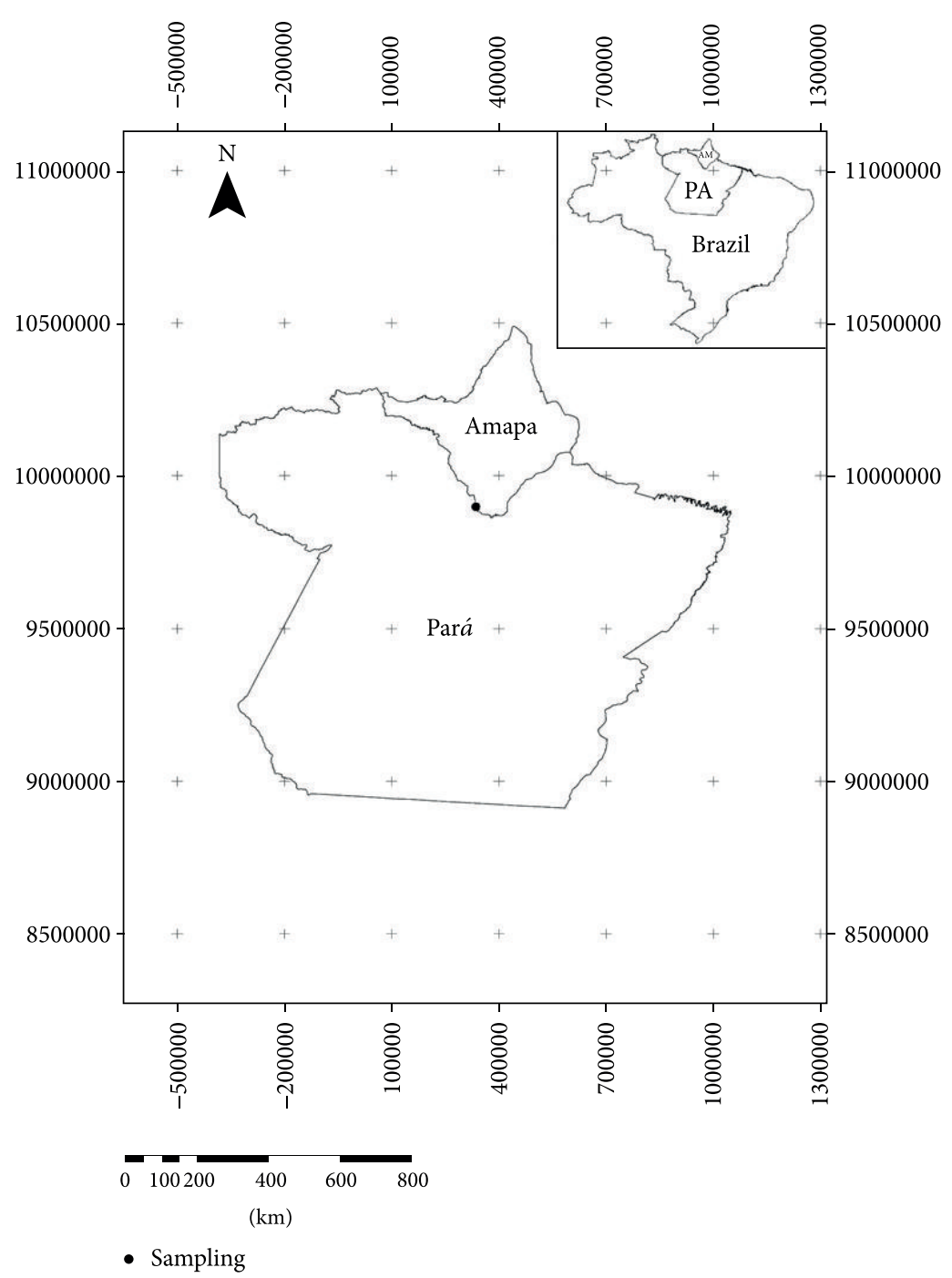

Figure 1: Study site. Source: adapted from Silva [38].

TABLE 2: Equations to estimate individual volume with bark.

\begin{tabular}{lc}
\hline Area code & Equation \\
\hline Stratum 001 & $\ln V=-11,145922+1,886699 \cdot \ln \mathrm{d} . \mathrm{b} . \mathrm{h} .+1,373333 \cdot \ln \mathrm{Ht}$ \\
Stratum 016 & $\ln V=-9,850475+1,7856259 \cdot \ln \mathrm{d} . \mathrm{b} . \mathrm{h} .+1,0923825 \cdot \ln \mathrm{Ht}$ \\
Stratum 026 & $\ln V=-10,162655+1,8427101 \cdot \ln \mathrm{d} . \mathrm{b} \cdot \mathrm{h} .+1,1041629 \cdot \ln \mathrm{Ht}$ \\
Stratum 041 & $\ln V=-10,636733+1,9185875 \cdot \ln \mathrm{d} . \mathrm{b} . \mathrm{h} .+1,2004476 \cdot \ln \mathrm{Ht}$ \\
Stratum 042 & $\ln V=-10,508245+1,883954 \cdot \ln \mathrm{d} . \mathrm{b} . \mathrm{h} .+1,1755465 \cdot \ln \mathrm{Ht}$ \\
Stratum 077 & $\ln V=-10,382205+1,8935363 \cdot \ln \mathrm{d} . \mathrm{b} . \mathrm{h} .+1,1283936 \cdot \ln \mathrm{Ht}$ \\
\hline
\end{tabular}

$V$ : volume with bark $\left(\mathrm{m}^{3}\right)$; d.b.h.: diameters, in centimeter and Ht: hight, in meters.

neural network training. In five measurements, this group totaled 8,735 cases (measurements of individual trees), as each plot had 53 trees on average throughout this evaluation. The second group was composed of the remaining 30 plots (10 in each productive capacity class) and was used for model validation. This group totaled 7,756 cases.

The annual mortality probability $\left(P_{m}\right)$ for each mensuration period was obtained by calculating the proportion of dead trees per diameter class, in-between mensuration, through the following equation [39-45]:

$$
P_{m}=\frac{n_{j 1}-n_{j 2}}{\sum_{i=1}^{j} n_{j 1}} \cdot 100,
$$

where $n_{j 1}$ is the number of living trees in the $j$ th diameter class, at the start of the period, $n_{j 2}$ is the number of living 
trees in the $j$ th diameter class at the end of the period. This stand was not observed ingrowth of trees.

Distance-independent competition indices $\left(\mathrm{IID}_{i}\right)$ being evaluated included $[2,40,46]$

$$
\begin{gathered}
\mathrm{IID}_{1}=\frac{\mathrm{d} \cdot \mathrm{b} \cdot \mathrm{h} \cdot_{\cdot}{ }^{2}}{\bar{D}^{2}}, \\
\mathrm{IID}_{2}=\frac{\mathrm{Ht}_{i}}{\overline{\mathrm{Ht}}}, \\
\mathrm{IID}_{3}=\frac{\left(\mathrm{d} \cdot \mathrm{b} \cdot \mathrm{h}_{\cdot i}{ }^{2} \mathrm{Ht}\right.}{\bar{D}^{2} \cdot \overline{\mathrm{Ht}}}, \\
\mathrm{IID}_{4}=\frac{\mathrm{d} \cdot \mathrm{b} \cdot \mathrm{h}_{\cdot}{ }^{2}}{q^{2}}, \\
\mathrm{IID}_{5}=\mathrm{BAL},
\end{gathered}
$$

where d.b.h. ${ }_{i}$ is diameter of the subject tree, $\bar{D}$ is arithmetic mean diameter of trees in the plot, $\mathrm{Ht}_{i}$ is total height of the subject tree, $\overline{\mathrm{H}}$ t is average total height of trees in the plot, $q$ is quadratic diameter, and $\mathrm{BAL}_{i}$ is aggregate basal area of trees larger than the subject tree.

2.2. Neural Network Training. Five hundred artificial neural networks were trained for the following output variables: annual mortality probability $\left(P_{m}\right)$, height at a future age $\left(\mathrm{Ht}_{2}\right)$, and diameter at a future age (d.b.h.2), using for each output variable a set with different input variables (Table 3 ).

For the training of artificial neural networks, software Statistica 8.0 [47] was used, testing different architectures of Multilayer Perceptron (MLP) networks.

MLP networks are feedforward multilayer networks having one or more layers of neurons between the input and output layers, known as hidden layer [48]. These hidden layers are able to extract nonlinear data patterns [49]. According to [28], with one hidden layer an MLP network can implement any continuous function, while two hidden layers enable approximating any function. In this network model, each neuron is connected to every neuron in the subsequent layer, but there are no connections between neurons within the same layer nor there is any feedback.

The feedforward type of training was used, by the supervised method. In this procedure, the data flow algorithm moves in only one, noncyclic direction, to initially define the synapse weights, excluding the input variables with lowweight synapses, while the supervised method indicates the input and output variables [28].

The training stages, such as preprocessing, actual training, with selection of architectures and stopping methods, and postprocessing, were performed by the optimization tool Intelligent Problem Solver (IPS), from software Statistica. 500 networks were initially trained in order to estimate each variable. Without precise and accurate networks, this number would be increased.

\begin{tabular}{|c|c|c|}
\hline Output variable & e Input variables & Number of trained networks \\
\hline \multirow{5}{*}{$P_{m}$} & $I_{1}, S, \mathrm{CLA}, \mathrm{IID}_{1}$ & 100 \\
\hline & $I_{1}, S, \mathrm{CLA}, \mathrm{IID}_{2}$ & 100 \\
\hline & $I_{1}, S, \mathrm{CLA}, \mathrm{IID}_{3}$ & 100 \\
\hline & $I_{1}, S, \mathrm{CLA}, \mathrm{IID}_{4}$ & 100 \\
\hline & $I_{1}, S, \mathrm{CLA}, \mathrm{IID}_{5}$ & 100 \\
\hline Total & & 500 \\
\hline \multirow{5}{*}{$\mathrm{Ht}_{2}$} & $I_{1}, I_{2}, S, \mathrm{Ht}_{1}, \mathrm{IID}_{1}$ & 100 \\
\hline & $I_{1}, I_{2}, S, \mathrm{Ht}_{1}, \mathrm{IID}_{2}$ & 100 \\
\hline & $I_{1}, I_{2}, S, \mathrm{Ht}_{1}, \mathrm{IID}_{3}$ & 100 \\
\hline & $I_{1}, I_{2}, S, \mathrm{Ht}_{1}, \mathrm{IID}_{4}$ & 100 \\
\hline & $I_{1}, I_{2}, S, \mathrm{Ht}_{1}, \mathrm{IID}_{5}$ & 100 \\
\hline Total & & 500 \\
\hline \multirow{5}{*}{ d.b.h. ${ }_{2}$} & $I_{1}, I_{2}, S$, d.b.h. ${ }_{1}, \mathrm{IID}_{1}$ & 100 \\
\hline & $I_{1}, I_{2}, S$, d.b.h. ${ }_{1}, \mathrm{IID}_{2}$ & 100 \\
\hline & $I_{1}, I_{2}, S$, d.b.h., $\mathrm{IID}_{3}$ & 100 \\
\hline & $I_{1}, I_{2}, S$, d.b.h. $._{1}, \mathrm{IID}_{4}$ & 100 \\
\hline & $I_{1}, I_{2}, S$, d.b.h. ${ }_{1}, \mathrm{IID}_{5}$ & 100 \\
\hline Total & & 500 \\
\hline
\end{tabular}

This software normalizes data in the range $0-1$ and tests various architectures and network models. In the supervised method, input and output variables are set by the user. In
TABLE 3: Output and input variables for neural network training.

$P_{m}$ : annual mortality probability; $\mathrm{Ht}_{2}$ : height at a future age $(\mathrm{m})$; d.b.h.2 diameter at a future age (cm); $I_{1}$ and $I_{2}$ : current and future ages (months); $S$ : site index $(\mathrm{m})$; CLA: diameter class in which the tree was $(\mathrm{cm})$; d.b.h. ${ }_{1}$ and $\mathrm{Ht}_{1}$ : current diameters $(\mathrm{cm})$ and heights $(\mathrm{m})$; and $\mathrm{IID}_{1}$ to $\mathrm{IID}_{5}$ : competition indices.

the feedforward procedure, the data flow algorithm moves in only one, noncyclic direction, to initially determine the synapse weights. The back-propagation algorithm corrects the initial synapse weights so as to minimize prediction error. Therefore, in this process, initial input variables can be excluded during training for not helping (low synapse weight) minimize prediction error [28].

The definition of network architecture, that is, number of neurons per layer, number of layers, and parameterization was optimized by the tool Intelligent Problem Solver, from software Statistica.

The selection of best network for each output variable was based on the following criteria [50-53]: (a) coefficient of correlation between observed and estimated values $\left(r_{y \hat{y}}\right)$, (b) coefficient of variation (CV \%), (c) root mean square error (RMSE), (d) bias, (e) bias \%, (f) absolute mean differences (AMD), and (g) graphic analysis of observed versus estimated values.

2.3. Validation. The validation of selected networks was done by annually projecting the tree mortality, the height and diameter of living trees, and the volume per hectare of plots until age of 72 months, according to the flowchart of basic steps and decisions for an individual tree model [2].

To verify network behavior under different growing conditions, the plots were divided into three productivity classes (high, medium, and low) based on site indices $(S)$ $(S=32 ; 26 ; 20 \mathrm{~m})$.

The tree mortality rule was the one that is used by Pretzsch et al., [54], whereby after estimating mortality 
TABLE 4: Architecture of artificial neural networks trained to obtain the mortality probability, height and diameter at future ages, and respective statistics.

\begin{tabular}{|c|c|c|c|c|c|c|c|c|c|c|}
\hline \multirow{2}{*}{ ANN } & \multirow{2}{*}{ Input variables } & \multicolumn{3}{|c|}{ Number of neurons (Layers) } & \multirow[b]{2}{*}{$r_{y \hat{y}}$} & \multirow{2}{*}{$\mathrm{CV} \%$} & \multirow{2}{*}{ RMSE } & \multirow{2}{*}{ Bias } & \multirow{2}{*}{ Bias \% } & \multirow{2}{*}{ AMD } \\
\hline & & Input & Hidden & Output & & & & & & \\
\hline \multicolumn{11}{|c|}{ Mortality probability $P_{m}$} \\
\hline$\overline{M_{1}}$ & $I_{1}, S$, CLA, IID $_{1}$ & 4 & 9 & 1 & 0.744 & 43.1 & 0.034 & 0.0004 & -16.91 & 0.0255 \\
\hline$M_{2}$ & $\mathrm{IID}_{2}$ & 1 & 3 & 1 & 0.579 & 52.3 & 0.041 & 0.0051 & -15.84 & 0.0305 \\
\hline$M_{3}$ & $I_{1}, S, \mathrm{CLA}, \mathrm{IID}_{3}$ & 4 & 8 & 1 & 0.799 & 38.6 & 0.030 & 0.0009 & -12.73 & 0.0235 \\
\hline$M_{4}$ & $I_{1}, S, \mathrm{CLA}, \mathrm{IID}_{4}$ & 4 & 5 & 1 & 0.711 & 45.2 & 0.037 & 0.0112 & 4.01 & 0.0286 \\
\hline$M_{5}$ & $I_{1}, \mathrm{CLA}, \mathrm{IID}_{5}$ & 3 & 4 & 1 & 0.790 & 39.3 & 0.031 & 0.0000 & -16.34 & 0.0244 \\
\hline \multicolumn{11}{|c|}{ Height $\left(\mathrm{Ht}_{2}\right)$} \\
\hline$\overline{H_{1}}$ & $S, \mathrm{Ht}_{1}, \mathrm{IID}_{1}$ & 3 & 6 & 1 & 0.993 & 3.0 & 0.626 & -0.0011 & -0.12 & 0.4370 \\
\hline $\mathrm{H}_{2}$ & $I_{1}, I_{2}, S, \mathrm{Ht}_{1}, \mathrm{IID}_{2}$ & 5 & 6 & 1 & 0.993 & 2.9 & 0.592 & -0.0089 & -0.17 & 0.4069 \\
\hline $\mathrm{H}_{3}$ & $I_{1}, I_{2}, S, \mathrm{Ht}_{1}, \mathrm{IID}_{3}$ & 5 & 7 & 1 & 0.994 & 2.6 & 0.532 & 0.0001 & -0.07 & 0.4048 \\
\hline $\mathrm{H}_{4}$ & $I_{1}, I_{2}, S, \mathrm{Ht}_{1}, \mathrm{IID}_{4}$ & 5 & 7 & 1 & 0.995 & 2.5 & 0.526 & -0.0028 & -0.10 & 0.3979 \\
\hline $\mathrm{H}_{5}$ & $I_{1}, I_{2}, S, \mathrm{Ht}_{1}, \mathrm{IID}_{5}$ & 5 & 9 & 1 & 0.993 & 2.9 & 0.608 & 0.0028 & -0.14 & 0.4222 \\
\hline \multicolumn{11}{|c|}{ Diameter (d.b.h.2 $)$} \\
\hline$D_{1}$ & $I_{1}, I_{2}$, d.b.h. $\cdot$ IID $_{1}$ & 4 & 5 & 1 & 0.990 & 4.6 & 0.618 & -0.0048 & -0.31 & 0.4089 \\
\hline$D_{2}$ & $I_{1}, I_{2}, S$, d.b.h. ${ }_{\cdot 1}, \operatorname{IID}_{2}$ & 5 & 7 & 1 & 0.990 & 4.4 & 0.601 & -0.0118 & -0.42 & 0.3986 \\
\hline$D_{3}$ & $I_{2}$, d.b.h.1, $\operatorname{IID}_{3}$ & 3 & 4 & 1 & 0.993 & 3.8 & 0.523 & 0.0008 & -0.31 & 0.3913 \\
\hline$D_{4}$ & $I_{1}, I_{2}, S$, d.b.h. ${ }_{\cdot 1}, \mathrm{IID}_{4}$ & 5 & 5 & 1 & 0.993 & 3.7 & 0.508 & -0.0021 & -0.25 & 0.3821 \\
\hline$D_{5}$ & $I_{1}, I_{2}, S$, d.b.h. ${ }_{\cdot 1}, \mathrm{IID}_{5}$ & 5 & 6 & 1 & 0.988 & 4.9 & 0.667 & 0.0013 & -0.28 & 0.5049 \\
\hline
\end{tabular}

$P_{m}$ : annual mortality probability; $\mathrm{Ht}_{2}$ : height at a future age $(\mathrm{m}) ;$ d.b.h. ${ }_{2}$ : diameter at a future age $(\mathrm{cm}) ; I_{1}$ and $I_{2}$ : current and future ages (months); $S$ : site index $(\mathrm{m})$; CLA: diameter class in which the tree was $(\mathrm{cm})$; d.b.h. ${ }_{1}$ and $\mathrm{Ht}_{1}$ : current diameters $(\mathrm{cm})$ and heights $(\mathrm{m})$; and $\operatorname{IID}_{1}$ to $\operatorname{IID}_{5}$ : competition indices.

probability for each tree, a random number between zero and one was generated $\left(P_{a}\right)$ and compared to the estimated mortality probability $\left(P_{m}\right)$. If $P_{m}>P_{a}$ the tree will die, otherwise the tree will remain alive and its dimensions should be projected to the next age through neural networks. The possibility of adding new trees was not considered.

In order to evaluate the accuracy of mortality estimates, a graphical analysis was performed of the estimated number of surviving trees in relation to observations. For the variables height and diameter, the F-test was used [55] $(\alpha=0.05)$, scatter plots were generated, and the statistics $r_{y \hat{y}}, \mathrm{CV} \%$, RMSE, bias, bias \%, AMD were calculated. Estimates of volume per hectare, as projected until age of 72 months in each productivity class, were compared to observed values using Student's $t$-test $(\alpha=0.05)$.

\section{Results}

3.1. Training of Artificial Neural Networks (ANNs). The network with the best performance to estimate annual mortality probability $P_{m}$ was $M_{5}$, with three neurons in the input layer (variables), four neurons in the hidden layer, and one neuron in the output layer. Although not with the best statistics (Table 4), this network provided a better trend regarding the distribution of observed values in relation to estimated values (Figure 2). With only the competition index as input variable, $M_{2}$ was the network with the poorest performance.

The best networks for the variables height and diameter were $\mathrm{H}_{4}$ and $\mathrm{D}_{4}$, respectively, with special mention of the estimate accuracy (Table 4 and Figure 2). The networks for these variables comprised five input layers (variables), seven and five hidden layers, respectively, and one output layer.

3.2. Validation. The projection of the number of surviving trees per hectare indicates a slight underestimation bias in the validation plots (Figure 3 ). The estimates can be considered reasonable, since mortality is a random event which is difficult to measure and estimate, consequently obstructing the good performance of probability models [56].

The neural networks selected for the variables diameter and height provided accurate estimates, regardless of the productivity class (Table 5 and Figure 4), with an error increase tendency as age advanced, due to error propagation. However, no difference was found between estimated and observed values, according to the $F$-test $(P<0.05)$.

Estimates of volume outside bark per hectare, as projected until age of 72 months (Figure 5), did not differ statistically from observed values $(P<0.05)$, in all productive capacity classes and ages, according to the $t$-test. Percentage differences between estimated and observed volumetric stocks at age of 72 months were $7 \%, 0 \%$, and $-6 \%$ for the high, medium, and low productivity class, respectively. Similarly to height and diameter estimates (Table 5), the older the age, the higher the error in volumetric stock estimates, due to error propagation.

\section{Discussion}

In recent decades, a major concern in the field of forest mensuration has been to develop growth and yield models using individual trees [40,57-60]. Modeling growth and yield 

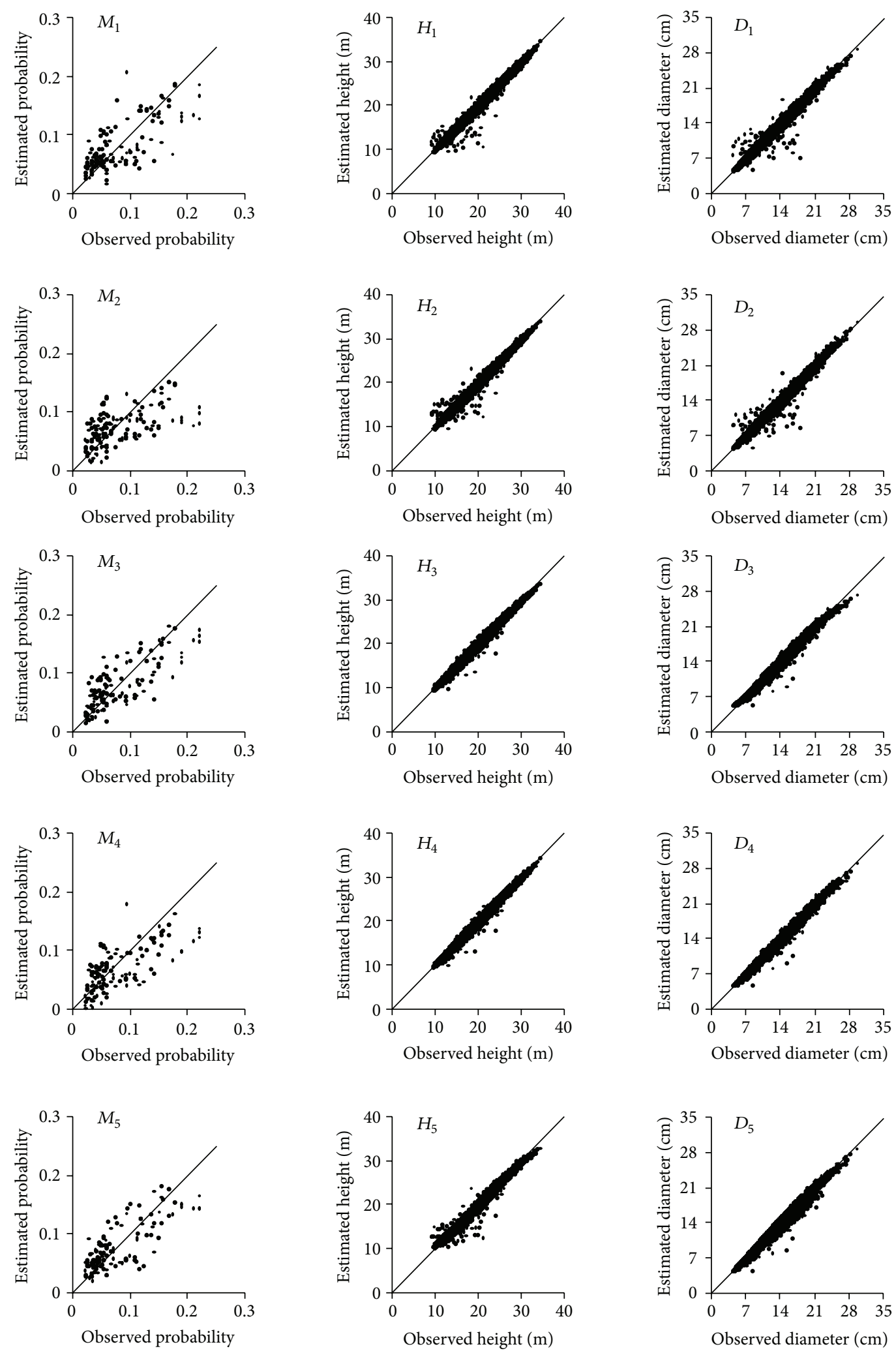

FIGURE 2: Mortality probability, height and diameter, as observed and estimated by artificial neural network training. 


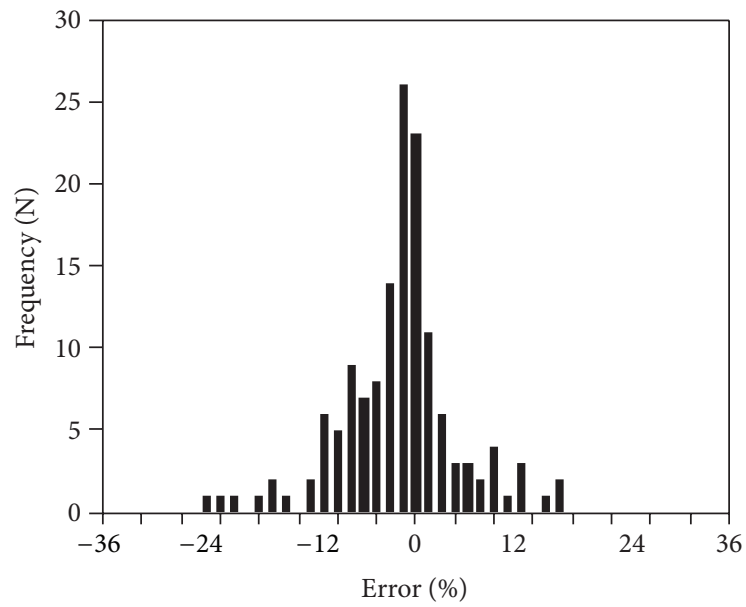

FIGURE 3: Histogram of residuals by the artificial neural network model for independent data (generalization).

TABLE 5: Statistics of height (Ht) and diameter (d.b.h.), as estimated and observed per age (months) and productive capacity class.

\begin{tabular}{|c|c|c|c|c|c|c|c|c|c|c|c|c|c|}
\hline \multirow{3}{*}{\multicolumn{2}{|c|}{ Productive capacity class Age (months) }} & \multicolumn{12}{|c|}{ Variable } \\
\hline & & \multicolumn{6}{|c|}{$\mathrm{Ht}(\mathrm{m})$} & \multicolumn{6}{|c|}{ d.b.h. $(\mathrm{cm})$} \\
\hline & & $r_{y \hat{y}}$ & $\mathrm{CV} \%( \pm)$ & RMSE & Bias & Bias \% & AMD & $r_{y \hat{y}}$ & $\mathrm{CV} \%( \pm)$ & RMSE & Bias & Bias $\%$ & AMD \\
\hline \multirow{4}{*}{$\operatorname{High}(S=32)$} & 36 & 0.979 & 3.5 & 0.707 & -0.080 & -0.489 & 0.456 & 0.976 & 5.5 & 0.767 & -0.081 & -0.856 & 0.516 \\
\hline & 48 & 0.965 & 4.6 & 1.040 & 0.027 & 0.003 & 0.741 & 0.961 & 7.1 & 1.065 & -0.016 & -0.443 & 0.752 \\
\hline & 60 & 0.953 & 5.1 & 1.272 & -0.223 & -1.067 & 0.930 & 0.945 & 8.5 & 1.379 & -0.184 & -1.642 & 0.961 \\
\hline & 72 & 0.934 & 5.9 & 1.540 & -0.153 & -0.784 & 1.159 & 0.925 & 10.3 & 1.748 & -0.211 & -1.890 & 1.248 \\
\hline \multirow{4}{*}{ Medium $(S=26)$} & 36 & 0.981 & 3.4 & 0.621 & 0.090 & 0.494 & 0.453 & 0.981 & 4.8 & 0.624 & 0.147 & 1.246 & 0.461 \\
\hline & 48 & 0.957 & 5.1 & 1.091 & 0.219 & 1.017 & 0.848 & 0.962 & 7.0 & 0.971 & 0.135 & 1.174 & 0.754 \\
\hline & 60 & 0.938 & 6.3 & 1.437 & 0.170 & 0.635 & 1.154 & 0.940 & 9.0 & 1.345 & 0.137 & 0.964 & 1.067 \\
\hline & 72 & 0.921 & 7.1 & 1.747 & 0.149 & 0.369 & 1.425 & 0.922 & 10.7 & 1.685 & 0.162 & 0.965 & 1.351 \\
\hline \multirow{4}{*}{ Low $(S=20)$} & 36 & 0.966 & 4.1 & 0.635 & 0.025 & 0.101 & 0.486 & 0.975 & 5.4 & 0.565 & 0.061 & 0.559 & 0.416 \\
\hline & 48 & 0.947 & 5.7 & 1.031 & 0.216 & 1.015 & 0.811 & 0.953 & 7.7 & 0.924 & 0.265 & 2.163 & 0.735 \\
\hline & 60 & 0.921 & 7.0 & 1.440 & 0.442 & 2.017 & 1.138 & 0.929 & 9.6 & 1.266 & 0.414 & 3.138 & 1.012 \\
\hline & 72 & 0.903 & 7.8 & 1.684 & 0.420 & 1.642 & 1.327 & 0.909 & 11.0 & 1.507 & 0.427 & 2.806 & 1.201 \\
\hline
\end{tabular}

can be difficult and complex if relying on individual trees as the basic modeling unit [61] due to the high resolution level required [62]. This type of modeling consists of establishing different equations to predict diameter and height growth as well as mortality, including tree- and stand-related data as explanatory variables which represent the competitive status of a tree [63-65], among others.

A widely used resource in this type of modeling is regression analysis through linear and nonlinear functions [6]. The different fit functions and the functional form with which these variables are included in the model are the greatest stumbling block to modeling growth and yield at the individual tree level. Numerous studies have been conducted to compare and provide the best fit function (linear and nonlinear) for predicting growth using different explanatory variables $[9,59,60,65,66]$. However, fitting these models requires knowledge of the functional relationship of variables, knowledge of modeling tools, in addition to accurate estimates. Even where such requirements are met, there is neither proven advantage of one function over another nor an indication of which are the most suitable explanatory variables to be used in the model, leading to uncertainty in growth and yield modeling for an individual tree. Additionally, the high resolution level of this model type is accompanied by problems caused by cumulative errors [62]. Therefore, using ANNs may work as an alternative to the traditional procedure for modeling an individual tree [31].

ANNs are increasingly becoming a popular tool in forest mensuration $[16,20,36]$ and in estimation of individual tree growth and yield $[30,31]$, requiring no presuppositions about the functional form of variables or fit functions. Instead, ANNs are trained to find such relationship. An ANN is capable of achieving optimum growth estimates without mentioning the functional form of the relationship between input and output layers [23]. Also, an ANN may help identify the most critical input variables to predict diameter and height growth as well as mortality probability and provide a better understanding of the dynamic of models at the individual tree level, becoming a valuable tool for Eucalyptus forest management.

A large number of authors have discussed the structure, technique, and operation of ANNs [18, 26, 27, 29]. Yet only 
High productivity $(S=32)$
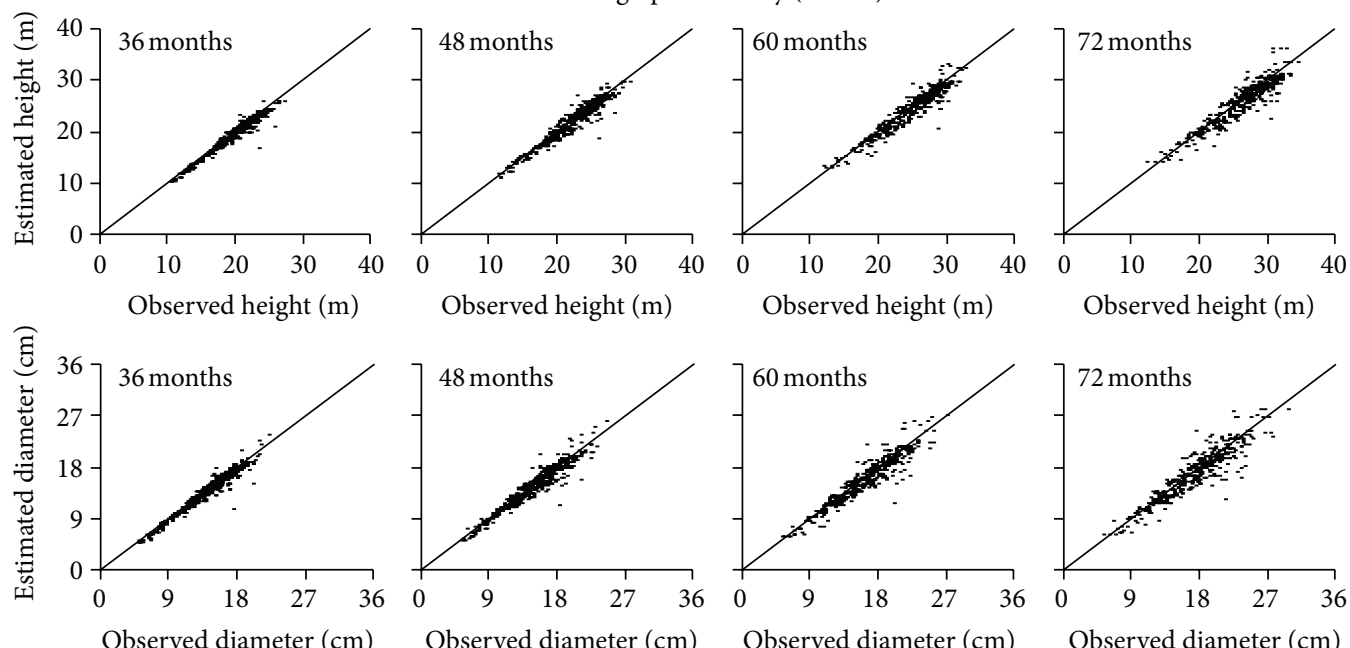

Observed diameter $(\mathrm{cm})$

Observed diameter $(\mathrm{cm})$

Medium productivity $(S=26)$
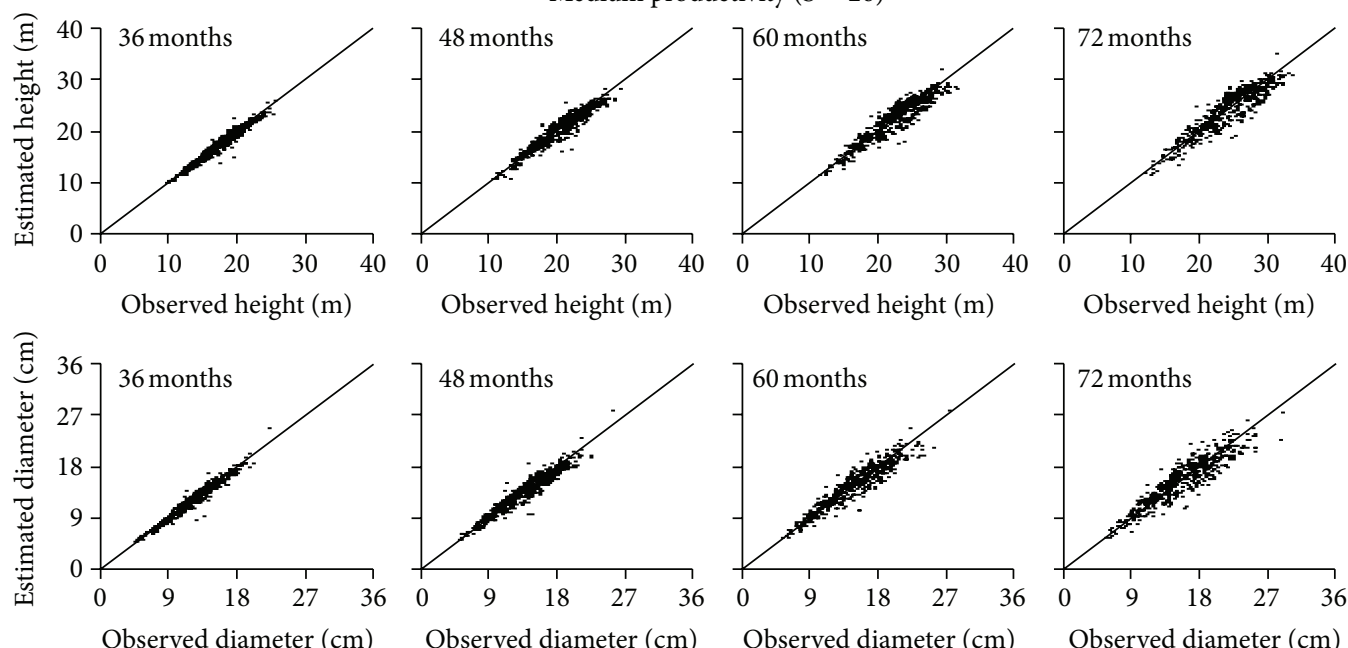

Observed diameter $(\mathrm{cm})$

Low productivity $(S=20)$
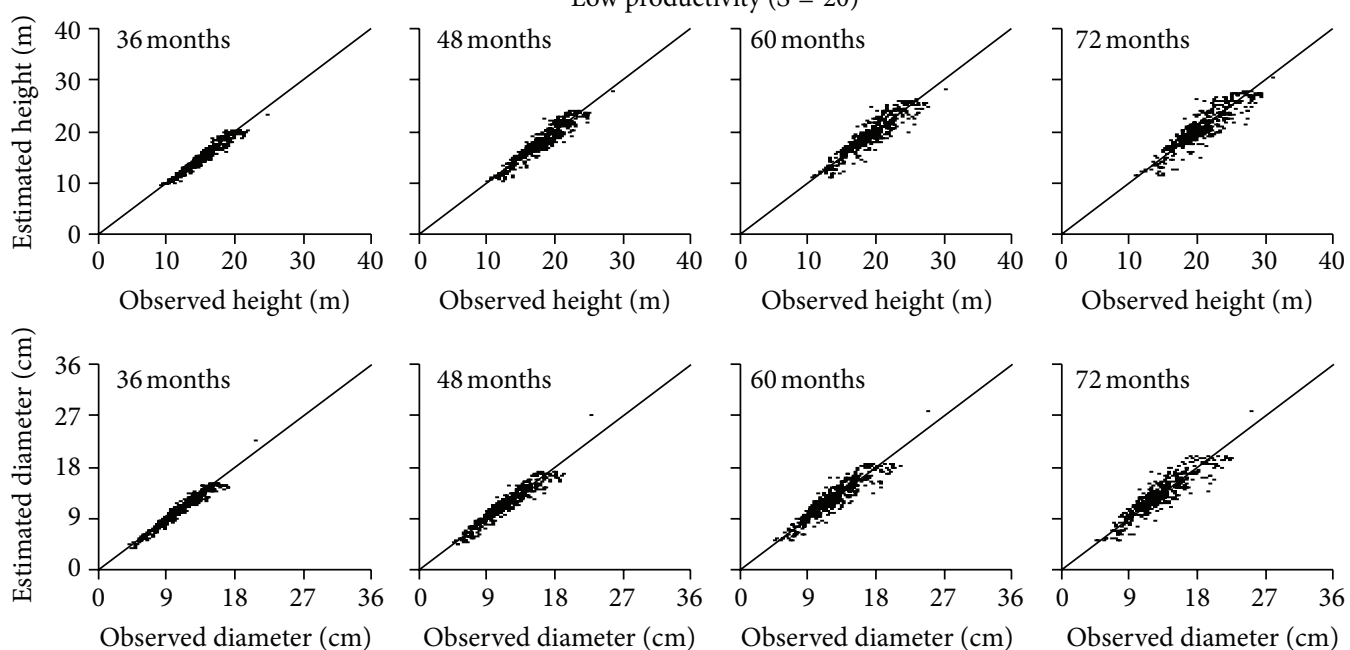

FIGURE 4: Heights and diameters, as observed and estimated per age and productivity class (high, medium, and low) by the artificial neural network model for independent data (generalization). 


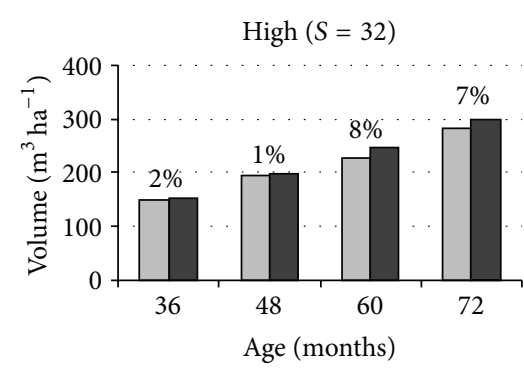

$\square$ Observed

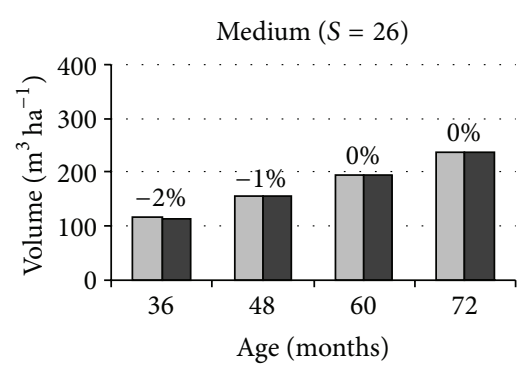

$\square$ Observed

- Estimated

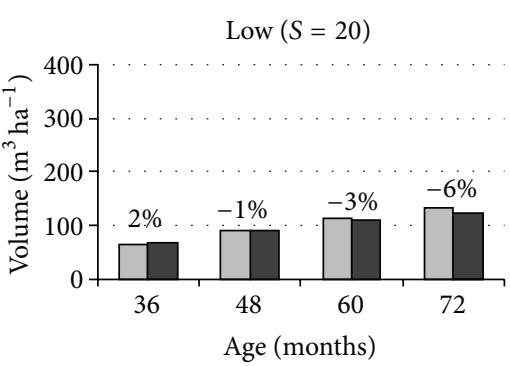

$\square$ Observed

- Estimated

FIGURE 5: Estimates of volume outside bark $\left(\mathrm{m}^{3} \mathrm{ha}^{-1}\right)$ per age (36-72) and productivity class (high, medium, and low). Values on the bars indicate the difference.

in the past decade interest in using ANNs has been stirred up, with an increasing number of practical applications in environmental and forest modeling [67]. Applications for use in forest mensuration and management include forest classification and mapping, growth and forest dynamics modeling, spatial data analysis, analysis of forest inventory types, and dendroclimatology modeling [25, 36, 68].

As far as results found in this study are concerned, the competition index of the network selected as best for mortality probability $\left(M_{5}\right)$ is $\mathrm{BAL}_{i}$, that is, the sum of basal areas of trees larger than the subject tree. According to this index, the smaller the tree is, the less competitive it is and the greater its mortality probability is [69-71]. Hasenauer et al. [19] found better prediction results for tree mortality using neural networks, in which $\operatorname{IID}_{5}$ (BAL) was one of the variables used in network training.

Studies involving individual tree mortality through regression models usually estimate mortality probability only as a function of the competition index as independent variable $[9,40,69,72]$. However, besides the competition index, Guan and Gertner [30], Monserud and Sterba [71], and Palahí and Pukkala [73] recommend using tree- and standrelated variables to improve mortality estimates. In this study, the networks with the best performance included these input variables (Table 4).

Network input variables for estimating height and diameter include the $\mathrm{IID}_{4}$, also known in literature as Basal Area Index (BAI). According to Daniels [58], this competition index was found to be the most correlated one with diameter and height growth in loblolly pine trees. Martins [9] observed that the $\mathrm{IID}_{4}$ provided the highest partial contribution, if compared to other competition indices, in diameter and height growth models for Eucalyptus trees. Explanations for best performance include the ease of calculation and the biological realism of the $\mathrm{IID}_{4}$ index.

Other than the competition index, tree- and stand-related variables such as age and site index are also widely used to express height and diameter growth at the individual tree level, using linear and nonlinear regression $[53,60,74]$. The selection of these variables in the best networks $\left(H_{4}, D_{4}\right)$ demonstrates realism in network estimates, adequately capturing height and diameter growth (Figure 3 and Table 4).
Martins [9] used the same data as this study for modeling individual trees yet using regression models. The fitted equations to estimate mortality probability were inferior if compared to the obtained statistics using artificial neural network training. As to the fitted equations to estimate diameter and height in future ages, the equations obtained using regression models were as accurate as the trained neural networks. However, in model validation, using independent data from regression fitting and network training, the projections of tree growth and mortality using the neural network model discussed in this work were proved to be superior. The bias $\%$ values at the individual tree level for height and diameter obtained by the previously mentioned author were in the order of $1.5 \%$, while in this work they were in the order of $0.5 \%$.

In the validation at the stand level, the percentage errors using artificial neural networks were in the order of $0.5 \%$, while those using regression models were in the order of $6 \%$ for total volume per hectare.

Since the same data were used, with the same methodology, it can be said that the tool artificial neural networks is effective in individual tree modeling and provides superior results if compared to regression models, particularly in the model generalization or validation stage.

Considering the results found, artificial neural networks should be studied for describing the structure and dynamics of natural tropical forests, with all of their complexity resulting from size and species diversity [3], which are usually difficult to model through traditional growth and yield methods.

\section{Conclusions}

Results in this study confirm the use potential of MLP artificial neural networks, through the supervised learning method, for individual tree modeling of commercial Eucalyptus plantations, given the precision of estimates found. Yet further investigation is required to improve this methodology, seeking to evaluate other types of artificial neural networks, as, for instance, RBF (Radial Bases Function) networks, and to study the effects of including qualitative input variables in the networks. 


\section{Acknowledgments}

The authors wish to thank Conselho Nacional de Desenvolvimento Científico e Tecnológico (CNPQ), Brazil, for granting the scholarship and Monica Castellani for English revision.

\section{References}

[1] J. L. Clutter, J. C. Fortson, L. V. Pienaar, G. H. Brister, and R. L. Bailey, Timber Management: A Quantitative Approach, John Wiley \& Sons, New York, NY, USA, 1983.

[2] L. S. Davis and K. N. Johnson, Forest Management, McGrawHill, New York, NY, USA, 1987.

[3] J. K. Vanclay, Modeling Forest Growth and Yield: Aplications to Mixed Tropical Forest, CAB International, Wallingford, UK, 1994.

[4] D. D. Munro, "Forest growth models-a prognosis," in Growth Models for Tree and Stand Simulation, J. Fries, Ed., pp. 1-21, Royal College of Forestry, Stockholm, Sweden, 1974.

[5] R. M. Newnham, The development of a stand model for Douglasfir [Ph.D. thesis], University of British Columbia, Canada, 1964.

[6] P. Soares and M. Tomé, "A distance dependent diameter growth model for first rotation eucalyptus plantation in Portugal," in Empirical and Process-Bases Models for Forest Tree and Stand Growth Simulation, A. Amaro and M. Tomé, Eds., pp. 267-270, Salamandra, 1997.

[7] F. Crescente-Campo, P. Soares, M. Tomé, and U. DiéguezAranda, "Modeling noncatastrophic individual tree mortality for Pinus radiate plantations in northwestern Spain," Forest Ecology and Management, vol. 257, no. 6, pp. 1542-1550, 2010.

[8] B. R. Mendes, N. Calegario, C. E. S. Volpato, and A. A. Melo, "Desenvolvimento de modelos de crescimento de árvores individuais fundamentado em equações diferenciais," Cerne, vol. 12, pp. 254-263, 2006.

[9] F. B. Martins, Modelagem de crescimento em nível de árvore individual para plantios comerciais de eucaliptos [Ph.D. thesis], Universidade Federal de Viçosa, Brazil, 2011.

[10] ABRAF-Associação Brasileira de Florestas Plantadas, "Anuário estatístico da ABRAF: ano base 2010. Brasília," 2011, http://www.abraflor.org.br/estatisticas/ABRAF11/ABRAF11-BR .pdf.

[11] M. A. Durlo, "Relações morfométricas para Cabralea canjerana (Well.) Mart," Ciencia Florestal, vol. 11, no. 1, pp. 141-149, 2001.

[12] J. B. Della Flora, M. A. Durlo, and P. Soathelf, "Modelo de crescimento para árvores singulares-Nectandra megapotamica (Spreng.) Mez," Ciencia Florestal, vol. 14, no. 1, pp. 165-177, 2004.

[13] M. A. Durlo, F. J. Sutili, and L. Denardi, "Modelagem da copa de Cedrela fissilis Vellozo," Ciencia Florestal, vol. 14, no. 2, pp. 79-89, 2004.

[14] T. Chassot, Modelos de crescimento em diâmetro de árvores individuais de Araucaria angustifólia (Bertol.) Kuntze na floresta ombrófila mista [Ph.D. thesis], Universidade Federal de Santa Maria, Brazil, 2009.

[15] J. C. C. Campos and H. G. Leite, Mensuração Florestal: Perguntas e Respostas, Universidade Federal de Viçosa, Viçosa, Brazil, 2009.

[16] P. Miehle, M. Battaglia, P. J. Sands et al., "A comparison of four process-based models and a statistical regression model to predict growth of Eucalyptus globulus plantations," Ecological Modelling, vol. 220, no. 5, pp. 734-746, 2009.
[17] D. Merkl and H. Hasenauer, "Using neural networks to predict individual tree mortality," in Proceedings of the Int'l Conference on Engineering Applications of Neural Networks, pp. 10-12, Gibraltar, UK, 1998.

[18] M. Weingartner, D. Merkl, and H. Hasenauer, "Improving tree mortality predictions of Norway Spruce stands with neural networks," in Proceedings of the Symposiun on Integration in Environmental Information Systems, Austria, 2000.

[19] H. Hasenauer, D. Merkl, and M. Weingartner, "Estimating tree mortality of Norway spruce stands with neural networks," Advances in Environmental Research, vol. 5, no. 4, pp. 405-414, 2001.

[20] M. J. Diamantopoulou, "Artificial neural networks as an alternative tool in pine bark volume estimation," Computers and Electronics in Agriculture, vol. 48, no. 3, pp. 235-244, 2005.

[21] E. Görgens, Estimação do volume de árvores utilizando redes neurais artificiais [Ph.D. thesis], Universidade Federal de Viçosa, Brazil, 2006.

[22] M. L. M. Silva, D. H. B. Binoti, J. M. Gleriani, and H. G. Leite, "Ajuste do modelo de Schumacher e Hall e aplicações de redes neurais artificiais para estimar volumes de árvores de eucalipto," Árvore, vol. 33, no. 6, pp. 1133-1139, 2009.

[23] J. M. Paruelo and F. Tomasel, "Prediction of functional characteristics of ecosystems: a comparison of artificial neural networks and regression models," Ecological Modelling, vol. 98, no. 2-3, pp. 173-186, 1997.

[24] M. Gevrey, I. Dimopoulos, and S. Lek, "Review and comparison of methods to study the contribution of variables in artificial neural network models," Ecological Modelling, vol. 160, no. 3, pp. 249-264, 2003.

[25] H. G. Leite, M. L. M. da Silva, D. H. B. Binoti, L. Fardin, and F. H. Takizawa, "Estimation of inside-bark diameter and heartwood diameter for Tectona grandis Linn. trees using artificial neural networks," European Journal of Forest Research, vol. 130, no. 2, pp. 263-269, 2011.

[26] A. P. Braga, Carvalho, A. C. P. L. F, and T. B. Ludemir, "Redes neurais artificiais," in Sistemas Inteligentes, S. O. Rezende, Ed., pp. 141-168, Manole, Barueri, Brazil, 2003.

[27] A. K. Jain, J. Mao, and K. M. Mohiuddin, "Artificial neural networks: a tutorial," Computer, vol. 29, no. 3, pp. 31-44, 1996.

[28] S. Haykin, Redes Neurais: Princípios e Prática, Bookman, Porto Alegre, Brazil, 2001.

[29] J. M. Barreto, Introdução às Redes Neurais Artificiais, Universidade Federal de Santa Catarina, Florianópolis, Brazil, 2002.

[30] B. T. Guan and G. Gertner, "Using a parallel distributed processing system to model individual tree mortality," Forensic Science, vol. 37, pp. 871-885, 1991.

[31] B. T. Guan and G. Gertner, "Modeling red pine tree survival with an artificial neural network," Forensic Science, vol. 37, pp. 14291440, 1991.

[32] D. L. Schomoudt, P. Li, and A. L. Abbot, "Machine vision using artificial neural networks with local 3d neighborhoods," Computers and Electronics in Agriculture, vol. 97, pp. 101-119, 1997.

[33] Q. B. Zhang, R. I. Hebda, Q. J. Zhang, and R. I. Alfaro, "Modeling tree-ring growth responses to climatic variables using artificial neural networks," Forest Science, vol. 46, no. 2, pp. 229-239, 2000.

[34] C. Liu, L. Zhang, C. J. Davis, D. S. Solomon, T. B. Brann, and L. E. Caldwell, "Comparison of neural networks and statistical methods in classification of ecological habitats using FIA data," Forest Science, vol. 49, no. 4, pp. 619-631, 2003. 
[35] S. A. Corne, S. J. Carver, W. E. Kunin, J. J. Lennon, and A. W. S. van Hees, "Predicting forest attributes in Southeast Alaska using artificial neural networks," Forest Science, vol. 50, no. 2, pp. 259276, 2004.

[36] R. Özçelik, M. J. Diamantopoulou, J. R. Brooks, and H. V. Wiant Jr., "Estimating tree bole volume using artificial neural network models for four species in Turkey," Journal of Environmental Management, vol. 91, no. 3, pp. 742-753, 2010.

[37] R. A. Demolinari, Crescimento de povoamentos de eucalipto não-desbastados [Ph.D. thesis], Universidade Federal de Viçosa, Viçosa, Brazil, 2006.

[38] M. G. Silva, Produtividade, idade e qualidade da madeira de Eucalyptus destinada à produção de polpa celulósica branqueada [Ph.D. thesis], Universidade de São Paulo, São Paulo, Brazil, 2011.

[39] T. D. Keister and G. R. Tidwell, "Competition ratio dynamics for improved mortality estimates in simulated growth of forests stands," Forest Science, vol. 21, pp. 46-51, 1975.

[40] G. R. Glover and J. N. Hool, "A basal area ratio predictor of loblolly pine plantation mortality," Forest Science, vol. 25, pp. 275-282, 1979.

[41] R. C. de Miranda, J. C. C. Campos, F. de Paula Neto, and L. M. de Oliveira, "Predição da mortalidade regular para eucalipto," Árvore, vol. 13, pp. 152-173, 1989.

[42] S. A. Machado, A. E. Tonon, A. F. Filho, and E. B. Oliveira, "Comportamento da mortalidade natural em bracatingais nativos em diferentes densidades iniciais e classes de sítio," Ciencia Florestal, vol. 12, pp. 41-50, 2002.

[43] R. Maestri, C. R. Sanquetta, and J. C. Arce, "Modelagem do crescimento de povoamentos de Eucalyptus grandisatravés de processos de difusão," Floresta, vol. 33, pp. 169-182, 2003.

[44] L. M. B. Rossi, H. S. Koehler, C. R. Sanquetta, and J. E. Arce, "Modelagem da mortalidade em florestas naturais," Floresta, vol. 37, pp. 275-291, 2007.

[45] D. Zhao, B. Borders, M. Wang, and M. Kane, "Modeling mortality of second-rotation loblolly pine plantations in the Piedmont/Upper coastal plain and lower coastal plain of the southern United States," Forest Ecology and Management, vol. 252, no. 1-3, pp. 132-143, 2007.

[46] A. R. Stage, "Prognosis model for stand development," USDA Forest Service Research Papers INT-137, USDA, Washington, DC, USA, 1973.

[47] StatSoft Inc, STATISTICA (data analysis software system), version 8. 0, 2007.

[48] R. P. Lippmann, "An introduction to computing with neural nets," IEEE ASSP Magazine, vol. 4, no. 2, pp. 4-22, 1987.

[49] A. P. Braga, Carvalho, A. P. L. F, and T. B. Ludemir, Redes Neurais Artificiais: Teoria e Aplicações, Rio de Janeiro, Rio de Janeiro, Brazil, 2000.

[50] R. G. D. Steel and J. H. Torrie, Principles and Procedures of Statistics, McGraw-Hill, New York, NY, USA, 1960.

[51] P. A. Murphy and H. S. Sternitzke, Growth and Yield Estimation for Loblolly Pine in the West Gulf, Southern Forest Experiment Station, New Orleans, La, USA, 1979.

[52] J. Siipilehto, "A comparison of two parameter prediction methods for stand structure in Finland," Silva Fennica, vol. 34, no. 4, pp. 331-349, 2000.

[53] A. Monty, P. Lejeune, and J. Rondeux, "Individual distanceindependent girth increment model for Douglas-fir in southern Belgium," Ecological Modelling, vol. 212, no. 3-4, pp. 472-479, 2008.
[54] H. Pretzsch, P. Biber, and J. Ďurský, "The single tree-based stand simulator SILVA: construction, application and evaluation," Forest Ecology and Management, vol. 162, no. 1, pp. 3-21, 2002.

[55] F. A. Graybill, Theory and Application of Linear Model, Duxbury, North Scituate, Mass, USA, 1976.

[56] D. A. Hamilton Jr., "A logistic model of mortality in thinned and unthinned mixed conifer stands of northern Idaho," Forest Science, vol. 32, no. 4, pp. 989-1000, 1986.

[57] I. E. Bella, "A new competition model for individual tree," Forest Science, vol. 17, pp. 364-372, 1971.

[58] R. F. Daniels, "Simple competition indices and their correlation with annual loblolly pine tree growth," Forest Science, vol. 22, pp. 454-456, 1976.

[59] H. Hasenauer and R. A. Monserud, "A crown ratio model for Austrian Forests," Forest Ecology and Management, vol. 84, no. 1-3, pp. 49-60, 1996.

[60] S. Vospernik, R. A. Monserud, and H. Sterba, "Do individualtree growth models correctly represent height: diameter ratios of Norway spruce and Scots pine?" Forest Ecology and Management, vol. 260, no. 10, pp. 1735-1753, 2010.

[61] H. Hasenauer, "Princípios para a modelagem de ecossistemas florestais," Revista Ciência \& Ambiente, vol. 20, pp. 53-69, 2000.

[62] Q. V. Cao, "Predictions of individual-tree and whole-stand attributes for loblolly pine plantations," Forest Ecology and Management, vol. 236, no. 2-3, pp. 342-347, 2006.

[63] M. Tome and H. E. Burkhart, "Distance-dependent competition measures for predicting growth of individual trees," Forest Science, vol. 35, no. 3, pp. 816-831, 1989.

[64] H. Hasenauer, R. A. Monserud, and T. G. Gregoire, "Using simultaneous regression techniques with individual-tree growth models," Forest Science, vol. 44, no. 1, pp. 87-95, 1998.

[65] M. S. González, RÍO, M. del, I. Cañellas, and G. Montero, "Distance independent tree diameter growth model for cork oak stands," Forest Ecology and Management, vol. 225, no. 1-3, pp. 262-270, 2006.

[66] K. Andreassen and S. M. Tomter, "Basal area growth models for individual trees of Norway spruce, Scots pine, birch and other broadleaves in Norway," Forest Ecology and Management, vol. 180, no. 1-3, pp. 11-24, 2003.

[67] C. H. Peng and X. Wen, Recent Applications of Artificial Neural Networks in Forest Resource Management: An Overview, American Association for Artificial Intelligence Technical, Menlo Park, Calif, USA, 1999.

[68] E. Dogan, B. Sengorur, and R. Koklu, "Modeling biological oxygen demand of the Melen River in Turkey using an artificial neural network technique," Journal of Environmental Management, vol. 90, no. 2, pp. 1229-1235, 2009.

[69] P. W. West, "Simulation of diameter growth and mortality in regrowth eucalypt forest of southern Tasmania," Forensic Science, vol. 27, pp. 603-616, 1981.

[70] D. W. Hann and C. H. Wang, Mortality Equations for Individual Trees in the Mixed-Conifer Zone of Southwest Oregon, vol. 67 of Research Bulletin, Forest Research Laboratory, Oregon, Wash, USA, 1990.

[71] R. A. Monserud and H. Sterba, "Modeling individual tree mortality for Austrian forest species," Forest Ecology and Management, vol. 113, no. 2-3, pp. 109-123, 1999.

[72] F. Crecente-Campo, P. Soares, M. Tomé, and U. DiéguezAranda, "Modelling annual individual-tree growth and mortality of Scots pine with data obtained at irregular measurement intervals and containing missing observations," Forest Ecology and Management, vol. 260, no. 11, pp. 1965-1974, 2010. 
[73] M. Palahí and T. Pukkala, "Optimising the management of Scots pine (Pinus sylvestris L.) stands in Spain based on individualtree models," Annals of Forest Science, vol. 60, no. 2, pp. 105-114, 2003.

[74] F. C. C. Uzoh and W. W. Oliver, "Individual tree height increment model for managed even-aged stands of ponderosa pine throughout the western United States using linear mixed effects models," Forest Ecology and Management, vol. 221, no. 13, pp. 147-154, 2006. 

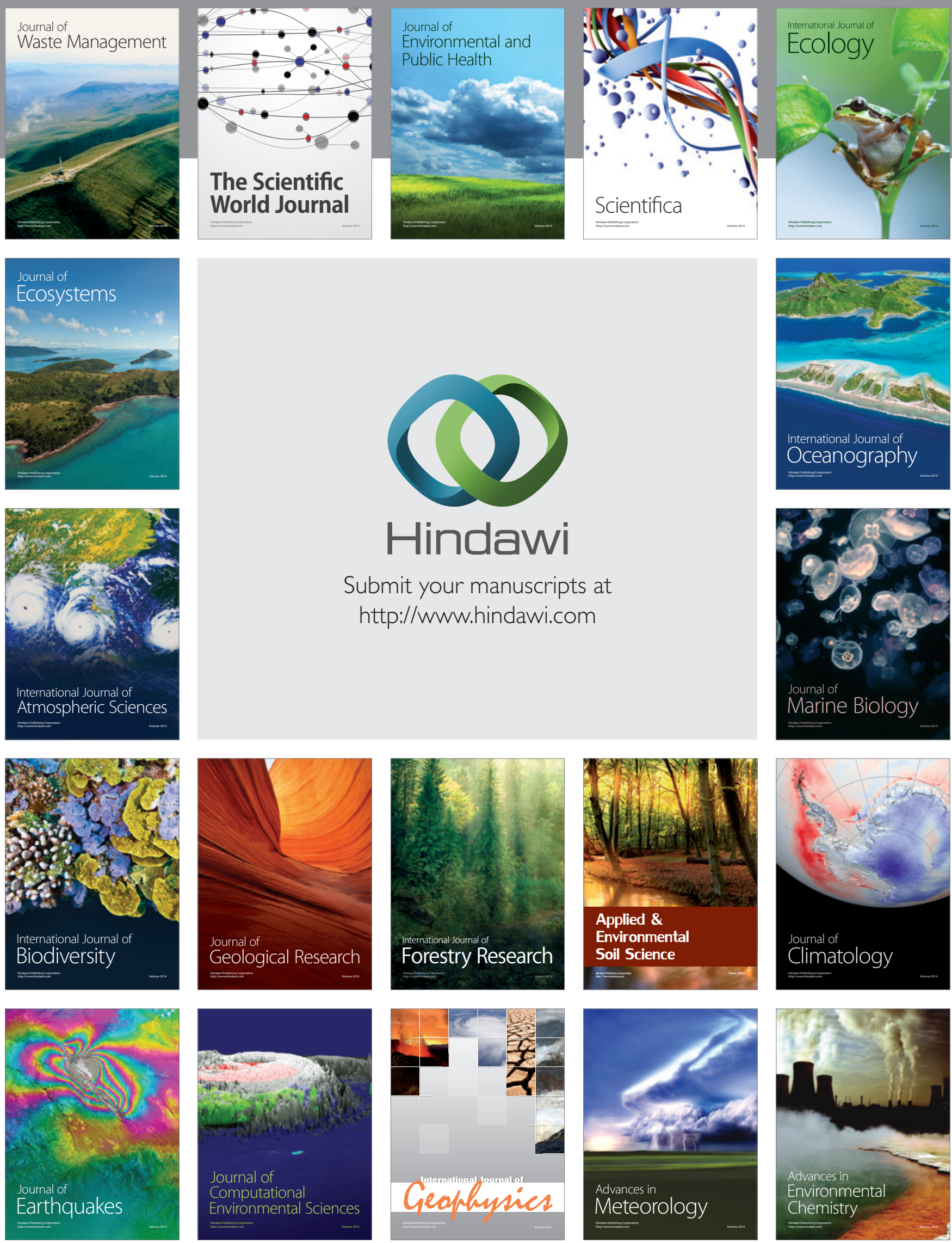